\title{
Influence of social support on older adults with cognitive impairment, depressive symptoms, or both coexisting
}

\author{
José C. Millán-Calenti, Alba Sánchez, Laura Lorenzo-López, Ricardo Cao, Ana Maseda
}

\begin{abstract}
The influence of social support dimensions (the extent of contact with others, the satisfaction with contacts, and the availability of help if sick or disabled) in elderly people with cognitive impairment (COG), depressive symptoms (DEP), or the co-occurrence of these symptoms (COG-DEP) was assessed in a cross-sectional analysis of a representative sample of 579 individuals aged 65 years and older. A lower extent of contact was related to COG (OR: 2.26). Fair satisfaction with contacts was related to DEP (OR: 2.88) and COG-DEP (OR: 4.22). A low level of satisfaction with contacts was an important predictor for DEP (OR: 7.99) and COG-DEP (OR: 7.88). Therefore, different dimensions of social support were independently correlated with different aspects of mental health. Quantitative aspects of social support were significantly linked to the presence of cognitive impairment. Satisfaction with social support affected depressive symptoms both alone and when they co-occurred with cognitive impairment.
\end{abstract}

Social support is a significant predictor of mental health in the elderly, affecting cognitive functioning (Holtzman, Rebok, Saczynski, Kouzis, Wilcox-Doyle, \& Eaton, 2004; Seeman, Albert, Lusignolo, \& Berkman, 2001; Yeh \& Liu, 2003) and emotional status (Brummett, Barefoot, Siegler, \& Steffens, 2000; Lee \& Shinkai, 2005; Leung, Chen, Lue, \& Hsu, 2007; Mechakra-Tahiri, Zunzunegui, Préville, \& Dubé, 2009; Prince, Harwood, Blizard, Thomas, \& Mann, 1997; Zunzunegui, Béland, \& Otero, 2001).

Social support is a multidimensional construct that includes quantitative (e.g., social network size and frequency of support behavior) and qualitative (e.g., satisfaction with contacts and perception that support will be provided if needed) aspects. In this sense, greater social resources have been associated with reduced cognitive decline in old age (Barnes, Mendes de Leon, Wilson, Bienias, \& Evans, 2004; Green, Rebok, \& Lyketsos, 2008), and interaction in larger networks has been positively related to the maintenance of global cognitive function for approximately 12 years (Holtzman et al., 2004). A relationship between perceived positive social support (Krueger, Wilson, Kamenetski, Barnes, Bienias, \& Bennett, 2009; Yeh \& Liu, 2003) or satisfaction with support (Hughes, Andel, Small, Borenstein, \& Mortimer, 2008) and higher cognitive function has also been observed among the elderly.

Moreover, previous studies have reported the importance of the quantitative (Chan, Malhotra, Malhotra, \& Østbye, 2011; Chiao, Weng, \& Botticello, 2011) and qualitative (Bisschop, Kriegsman, Beekman, \& Deeg, 2004; Chi \& Chou, 2001; Cornman, Goldman, Glei, Weinstein, \& Chang, 2003) aspects of social support in predicting depressive symptomatology in older adults. Nevertheless, qualitative aspects of the supporting relationship, including satisfaction with the support received, have been identified as important in preventing depression among elderly individuals than quantitative support (Chao, 2011; Chi \& Chou, 2001).

In the elderly population, cognitive impairment and depressive disturbances are frequently associated with each other (Gabryelewicz, Styczynska, Pfeffer, Wasiak, Barczak, Luczywek, et al., 2004; Steffens \& Potter, 2008). However, few studies in the literature have attempted to determine the risk factors that predict the occurrence of both diseases. Recently, the co-occurrence of cognitive impairment and depressive symptoms was explained by functional dependence and the presence of chronic diseases, such as cerebrovascular disease, congestive heart failure, and diabetes (Millán-Calenti, Maseda, Rochette, Valzquez, Sanchez, \& Lorenzo, 2011). With regard to social variables, dissatisfaction with social support increased the risk of co-occurrence of depressive symptomatology and cognitive impairment (Fuhrer, Antonucci, \& Dartigues, 1992); however, to the best of our knowledge, little is known about the effect of other components of social support.

The aim of this study was to examine the influence of several social support dimensions (the extent of contact with others, the satisfaction with contacts, and the availability of help if sick or disabled) on the 
presence of cognitive impairment alone (COG), depressive symptoms alone (DEP), and the co-occurrence of both sets of symptoms (COG-DEP) in elderly individuals.

\section{Method}

\section{Selection and Description of Participants}

The current cross-sectional study included a representative sample of 600 community-dwelling residents of Narón Council (A Coruña, Spain), aged 65 years and older. Participants were selected from the Municipal Register using a random number table and were grouped by 5 -year age intervals and by gender based on the council census (Table 1). The Municipal Register saves and exploits the information of the administrative recordings grouping to ensure the confidentiality and privacy of individuals, and includes information for the entire population (not only those aged 65 years and older).

Table 1. Distribution (Number of Participants in Each Category Group) of the Population and the Study Sample in Narón (INE, 2000) by Age and Gender

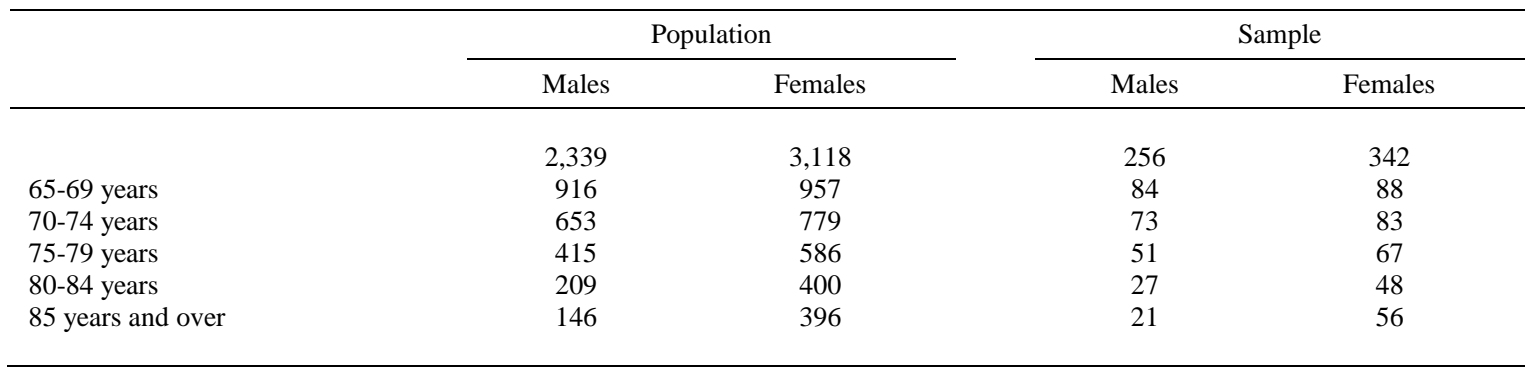

The confidence level was $95 \%$, the sampling error was $\pm 4 \%$, and the estimate for missing data was $10 \%$. The mean age was $75.1 \pm 7.5$ years $(75.9 \pm 8.0$ years for females $(57.2 \%)$ and $73.9 \pm 6.7$ years for males). In Table 2, characteristics of the sample according to cognitive state and depressive symptoms are reported. As shown in Table 2, 12.6\% of participants were cognitively impaired, $17.3 \%$ of participants had depressive symptoms, and $7.9 \%$ of participants suffered the co-occurrence of both depressive symptoms and cognitive impairment. 
Table 2. Characteristics of Elderly Subjects with Cognitive Impairment Alone (COG), Depressive Symptoms Alone (DEP), and Both Sets of Symptoms (COG-DEP), or No Cognitive Impairment or Depressive Symptoms (NCOG-NDEP)

\begin{tabular}{|c|c|c|c|c|}
\hline & $\begin{array}{c}\mathrm{COG} \\
\mathrm{N}=73(12.6 \%)\end{array}$ & $\begin{array}{c}\text { DEP } \\
\mathrm{N}=100(17.3 \%)\end{array}$ & $\begin{array}{c}\text { COG-DEP } \\
\mathrm{N}=46(7.9 \%)\end{array}$ & $\begin{array}{c}\text { NCOG-NDEP } \\
\mathrm{N}=360(62.2 \%)\end{array}$ \\
\hline Age & $\mathrm{N}(\%)$ & $\mathrm{N}(\%)$ & $\mathrm{N}(\%)$ & $\mathrm{N}(\%)$ \\
\hline Men & $24(32.9)$ & $26(26.0)$ & $9(19.6)$ & 194 (53.9) \\
\hline Women & $49(67.1)$ & $74(74.0)$ & $37(80.4)$ & $166(46.1)$ \\
\hline \multicolumn{5}{|l|}{ Educational level } \\
\hline No formal education & $63(87.5)$ & $94(94.0)$ & $41(93.2)$ & $289(80.7)$ \\
\hline Primary & $7(9.7)$ & $5(5.0)$ & $2(4.5)$ & $55(15.4)$ \\
\hline${ }^{3}$ Secondary & $2(2.8)$ & $1(1.0)$ & $1(2.3)$ & $14(3.9)$ \\
\hline Absent & $42(57.5)$ & $56(56.0)$ & $11(23.9)$ & $282(78.3)$ \\
\hline Present & $31(42.5)$ & $44(44.0)$ & $35(76.1)$ & $78(21.7)$ \\
\hline \multicolumn{5}{|l|}{ Chronic diseases (CCI) } \\
\hline$<2$ & $24(32.9)$ & $15(15.0)$ & $12(26.1)$ & $120(33.3)$ \\
\hline 32 & $49(67.1)$ & $85(85.0)$ & $34(73.9)$ & $240(66.7)$ \\
\hline
\end{tabular}

Note: M, Sample mean; SD, Standard deviation; IADL, Instrumental Activities of Daily Living; ADL, Basic Activities of Daily Living; CCI, Charlson Comorbidity Index.

\section{Measures}

The Spanish version (Grau, Eiroa, \& Cayuela, 1996) of the standardized Older Americans Resources and Services (OARS) Social Resources Scale (Fillenbaum, 1988) was used to rate the adequacy of social support. The cross-cultural adaptation process of the instrument made by Grau et al. (1996) did not modify the questionnaire or its internal validity. Nevertheless, the Spanish adaptation showed that items included in the social network dimension measured characteristics that were not strongly related to each other, because the items represented quite different aspects of the definition of a social network. Thus, the construct heterogeneity of the social network variable is high, but there are few items that can be used to measure it. The scale's homogeneity would improve with the addition of more items.

This scale consists of seven items, and raw scores are coded on a scale based on the following six categories: (a) excellent, (b) good, (c) mild impairment, (d) moderate impairment, (e) severe impairment, and (f) total impairment. This scale comprises three psychometrically identified subscales that can be used separately, providing a new approach for the examination of specific aspects of social resources. Based on the work of Fillenbaum (1988), we utilized a regression-based equation (entering the values for the relevant items and then weighting them in a regression equation), which is likely to be more consistent (reliable) than the manual assignment of scores. The information from all three scales can be combined into a 6-point summary measure. These three validated social resources subscales (Fillenbaum, 1988), derived from the 7-item SOC, include the extent of contact with others ("Number of people known well enough to visit," "Times talking with someone on telephone per week," "Times visiting with someone per week"), the satisfaction with contacts ("Have someone you trust," "Frequency of feelings of loneliness," "Satisfaction with contact with loved ones"), and the availability of help when needed ("Have someone who would help you if sick or disabled"). The raw scores of these subscales were calculated by summing responses to the questions related to each dimension and then transformed into the following categories: from 1 (few) to 3 (extensive) for the extent of contact with others, from 1 (unsatisfactory) to 3 (very satisfactory) for the satisfaction with contacts, and from 0 (none) to 3 (long term) for the availability of help.

Cognitive status was assessed using the Mini-Mental State Examination (MMSE) (Folstein, Folstein, $\&$ McHugh, 1975), which is widely used in the Spanish population. Cognitive impairment was defined according to Crum's median cut-off scores, accounting for age and educational level (Crum, Anthony, Bassett, \& Folstein, 1993). Applying the age or level of education distribution, rather than using the cutoff point of 23/24, minimizes the differences found when comparing the results from the 30-point Folstein's Mini-Mental State Examination with the results from its validated and slightly modified 
Spanish translation, the 35-point Lobo's Mini-Examen Cognoscitivo (MEC; Lobo, Ezquerra, Gómez Burgada, Sala, \& Seva Diaz, 1979). In particular, accounting for age and the level of education avoided the possibility of obtaining "false positives" in subjects with a low educational level or aged 80 years or older (Vinyoles Bargalló et al., 2002).

Nine subjects with a minimal level of consciousness were excluded from the random sample because they could not be assessed by the MMSE

The Geriatric Depression Scale-Short Form (GDS-SF; Sheikh \& Yesavage, 1986) was used to assess depressive symptoms. It was scored to yield a continuous scale from 0 to 15 , with 6 or higher indicating probable clinical depression (Herrmann, Mittman, Silver, Shulman, Busto, Shear, et al., 1996). Due to data losses, 12 additional individuals were excluded from the study, thus, the final analysis sample was 579.

A number of confounders were selected to examine the relationships between social support and mental health. Demographic variables (age, gender, and educational level) were assessed using the OARS (Duke University, 1978). Functional status was measured using the basic activities of daily living (ADL; Katz, Ford, Moskowitz, Jackson, \& Jaffe, 1963) and the instrumental activities of daily living (IADL; Lawton \& Brody, 1969) scores. Based on these scores, individuals who were unable to perform any of the activities were considered as functionally incapacitated for that activity (ADL- or IADL-dependent). One important issue to take into account is that gender factors strongly influence responses to the IADL measure in the Spanish population. To avoid this con- found, we took into consideration the latent ability to perform a task, to correct for the possibility that gender could account for a functional disability. Thus, the items were phrased as "Can you ...?" rather than "Do you ...?" Therefore, the current study employed the latent-ability or "could do" approach in IADL use, which has the advantage of addressing environmental barriers and other contextual factors that may inhibit performance.

Medical histories were collected by a physician or a trained nurse in charge of the participant during the research. Participants' reports were provided by the patients or their relatives according to medical records. General comorbidity and number of comorbid diseases were registered using the Charlson comorbidity index (CCI; Charlson, Pompei, Ales, \& MacKenzie, 1987), and the health conditions of interest were included in the CCI.

\section{Procedure}

Participants were individually assessed in a health center or at home in the case of people with mobility difficulties. A medical doctor (practitioner) and/or a trained nurse with extensive experience conducted the clinical evaluation. The doctor was in charge of some of the patients during the research and also contacted additional practitioners to follow the medical history of the other subjects to provide comprehensive ongoing knowledge of each patient's status. Subjects without medical records from their respective practitioner were interviewed by the research doctor to establish their medical history. The participants' overall personal functional status and service use were assessed with a questionnaire based on the standardized Older Americans Resources and Services Multidimensional Functional Assessment Questionnaire by an occupational therapist. The Mini-Mental State Examination and the Geriatric Depression Scale-Short Form were administered by a qualified clinical psychologist with extensive experience in cognitive assessment.

Prior to the data collection, all participants were informed about the study and signed the corresponding informed consent form. The study protocol was approved by the Ethics Committee at the University of A Coruña and conformed to the principles embodied in the Declaration of Helsinki.

\section{Statistical Analysis}

Characteristics of the sample were summarized in terms of frequency and percentage for the categorical variables, and ordinal and continuous variables were summarized as the mean \pm SD .

A multinomial logistic regression analysis was used to determine how the different components of social support affect cognitive impairment, depressive symptoms, and the co-occurrence of both sets of symptoms, while also controlling for age, gender, level of education, functional status, and comorbidity.

Odds ratios (OR) and 95\% confidence intervals (CI) were calculated for each covariate included in the model. Statistical significance was set at a $p$ value of less than 0.05 . Statistical analysis was performed using the Statistical Package for the Social Sciences (SPSS) version 16.0.1 (SPSS Inc, 2007). 


\section{Results}

Scores on the social resources scale are presented in Table 3 as a function of the participants' cognitive state and depressive symptoms.

Table 3. Social Resources of Elderly Subjects with Cognitive Impairment Alone (COG), Depressive Symptoms Alone (DEP), cooccurrence of Both Sets of Symptoms (COG-DEP), or No Cognitive Impairment or Depressive Symptoms (NCOG-NDEP)

\begin{tabular}{|c|c|c|c|c|}
\hline & $\begin{array}{c}\mathrm{COG} \\
\mathrm{N}= \\
\mathrm{N} 312.6 \%) \\
\mathrm{N}(\%)\end{array}$ & $\begin{array}{c}\mathrm{DEP} \\
\mathrm{N}=10017.3 \%) \\
\mathrm{N}(\%)\end{array}$ & $\begin{array}{c}\text { COG-DEP } \\
\mathrm{N}=46(7.9 \%) \\
\mathrm{N}(\%)\end{array}$ & $\begin{array}{c}\text { NCOG-NDEP } \\
\mathrm{N}=360(62.2 \%) \\
\mathrm{N}(\%)\end{array}$ \\
\hline \multicolumn{5}{|l|}{ Social resources (SOC) } \\
\hline Excellent & $9(12.7)$ & $11(11.0)$ & $1(2.2)$ & $110(30.7)$ \\
\hline Good & $38(53.5)$ & $38(38.0)$ & $15(32.6)$ & $166(46.4)$ \\
\hline Severe impairment & $2(2.8)$ & $2(2.0)$ & $1(2.2)$ & $10(2.8)$ \\
\hline Total impairment & $2(2.8)$ & $5(5.0)$ & $1(2.2)$ & $3(0.8)$ \\
\hline \multicolumn{5}{|c|}{ Extent of contact with others } \\
\hline Few & $40(56.3)$ & $44(44.0)$ & $26(56.5)$ & $97(27.0)$ \\
\hline Adequate & $12(16.9)$ & $15(15.0)$ & $11(23.9)$ & $67(18.7)$ \\
\hline Extensive & $19(26.8)$ & $41(41.0)$ & $9(19.6)$ & $195(54.3)$ \\
\hline \multicolumn{5}{|c|}{ Availability of help if sick or disabled } \\
\hline None & $4(5.6)$ & $6(6.0)$ & $2(4.3)$ & $12(3.3)$ \\
\hline Occasional & - & $2(2.0)$ & - & $10(2.8)$ \\
\hline Short term & $2(2.8)$ & $2(2.0)$ & $2(4.3)$ & $3(0.8)$ \\
\hline Long term & 66 (91.6) & $90(90.0)$ & $42(91.4)$ & $334(93.1)$ \\
\hline
\end{tabular}

Note: SOC, Social Resources Scale.

As shown in the Table 3, 12.7\% of the cognitively impaired (COG) participants reported an excellent level of social resources, in contrast with $53.5 \%$, who reported a good level and $28.2 \%$, who reported a mild impairment level. More than half of the participants $(56.3 \%)$ reported their extent of contact with others as limited. In terms of satisfaction, $45.8 \%$ of the COG participants were fairly satisfied with their contacts, and $52.8 \%$ were very satisfied. Of this sample, $91.6 \%$ of the participants in this group reported the long-term availability of someone who could provide help if they were sick or disabled.

In the group with depressive symptoms alone (DEP), social resources were considered excellent $(11.0 \%)$, good $(38.0 \%)$, or mildly impaired $(42.0 \%)$. Of this group, $41.0 \%$ reported their contact with others as extensive, and $44.0 \%$ reported having little contact with others. With regard to satisfaction with contacts, $22.0 \%$ of DEP participants were unsatisfied, and $57.0 \%$ were fairly satisfied. Of these participants, $90.0 \%$ reported the long-term availability of someone who could provide help if the were sick or disabled.

Finally, in the DEP-COG group with the co-occurrence of depressive symptoms and cognitive impairment, $32.6 \%$ of the participants reported good social resources, and $58.7 \%$ of the participants reported mildly impaired social resources. Of this group, 56.6\% reported their extent of contact with others as limited, and $67.4 \%$ were fairly satisfied with their level of contact. In addition, $91.3 \%$ of the DEP-COG participants reported the long-term availability of some - one who could provide help if they were sick or disabled.

Potential covariates likely to influence outcomes were first tested in bivariate models and then included in a multivariate model when significant. Table 4 displays the results of the multinomial logistic regression to model the effect of the three social support dimensions on the COG, DEP, and COG-DEP groups after adjusting for sociodemographic variables, functional status, and medical comorbidity. 
Table 3. Social Resources of Elderly Subjects with Cognitive Impairment Alone (COG), Depressive Symptoms Alone (DEP), cooccurrence of Both Sets of Symptoms (COG-DEP), or No Cognitive Impairment or Depressive Symptoms (NCOG-NDEP)

\begin{tabular}{|c|c|c|c|c|}
\hline & $\begin{array}{c}\mathrm{COG} \\
\mathrm{N}=73(12.6 \%) \\
\mathrm{N}(\%)\end{array}$ & $\begin{array}{c}\text { DEP } \\
\mathrm{N}=100(17.3 \%) \\
\mathrm{N}(\%)\end{array}$ & $\begin{array}{c}\text { COG-DEP } \\
\mathrm{N=} 46(7.9 \%) \\
\mathrm{N}(\%)\end{array}$ & $\begin{array}{c}\text { NCOG-NDEP } \\
\mathrm{N}=360(62.2 \%) \\
\mathrm{N}(\%)\end{array}$ \\
\hline \multicolumn{5}{|l|}{ Social resources (SOC) } \\
\hline Excellent & $9(12.7)$ & $11(11.0)$ & $1(2.2)$ & $110(30.7)$ \\
\hline Good & $38(53.5)$ & $38(38.0)$ & $15(32.6)$ & $166(46.4)$ \\
\hline Severe impairment & $2(2.8)$ & $2(2.0)$ & $1(2.2)$ & $10(2.8)$ \\
\hline Total impairment & $2(2.8)$ & $5(5.0)$ & $1(2.2)$ & $3(0.8)$ \\
\hline \multicolumn{5}{|c|}{ Extent of contact with others } \\
\hline Few & $40(56.3)$ & $44(44.0)$ & $26(56.5)$ & $97(27.0)$ \\
\hline Adequate & $12(16.9)$ & $15(15.0)$ & $11(23.9)$ & $67(18.7)$ \\
\hline Extensive & $19(26.8)$ & $41(41.0)$ & $9(19.6)$ & $195(54.3)$ \\
\hline Very satisfactory & $38(52.8)$ & $21(21.0)$ & $6(13.0)$ & $199(55.2)$ \\
\hline \multicolumn{5}{|c|}{ Availability of help if sick or disabled } \\
\hline None & $4(5.6)$ & $6(6.0)$ & $2(4.3)$ & $12(3.3)$ \\
\hline Occasional & - & $2(2.0)$ & - & $10(2.8)$ \\
\hline Short term & $2(2.8)$ & $2(2.0)$ & $2(4.3)$ & $3(0.8)$ \\
\hline Long term & $66(91.6)$ & $90(90.0)$ & $42(91.4)$ & $334(93.1)$ \\
\hline
\end{tabular}

Note: SOC, Social Resources Scale.

As shown, the participants who reported that their extent of contact with others was limited were more likely ( OR : 2.26, 95\% CI: 1.17-4.38) to suffer COG. Fair satisfaction with contacts was significantly related to DEP ( OR : 2.88, 95\% CI: 1.64-5.05) and COG-DEP ( OR : 4.22, 95\% CI: 1.61-11.04). In addition, a low satisfaction with contacts was a significant predictor of DEP ( OR : 7.99, 95\% CI: 3.6617.47) and COG-DEP ( OR : 7.88, 95\% CI: 2.30-26.97). In contrast, a low satisfaction with contacts was inversely related to COG ( OR : $0.07,95 \% \mathrm{CI}$ : 0.01-0.58). The availability of someone who could provide help if the participant was sick or disabled was not linked to changes for any of the study groups.

\section{Discussion}

The results from this randomly selected representative sample support the importance of social support for the mental health of elderly individuals.

With regard to the first dimension of social support, the extent of contact with others, the findings provide evidence that a person with limited contact with others is more likely to develop cognitive impairment. In contrast, no significant association was found between the extent of contact and the presence of depressive symptoms or the co-occurrence of cognitive impairment and depressive symptoms.

In the existing literature, there is a discrepancy about the relationship between the quantitative aspects of social support and cognitive functioning. Several studies suggested that maintaining many social connections and activities may help to prevent or postpone cognitive deterioration in old age (Bassuk, Glass, \& Berkman, 1999; Crooks, Lubben, Petitti, Little, \& Chiu, 2008; Fratiglioni, Wang, Ericsson, Maytan, \& Winblad, 2000; Zunzunegui, Alvarado, Del Ser, \& Otero, 2003). In contrast, other authors found that none of the social network measures were related to cognitive impairment (Glei, Landau, Goldman, Chuang, Rodriguez, \& Weinstein, 2005; Krueger et al., 2009). Discrepancies between these results may be due to study differences based on the definition and assessment of social networks.

Several hypotheses have been proposed to explain the relationship between social networks and cognitive functioning. The cognitive reserve hypothesis suggests that aspects of life experiences, such as engagement in social leisure activities, may supply cognitive reserves, resulting in a slower cognitive decline in healthy elderly individuals (Scarmeas \& Stern, 2003). Social networks, as positive social relationships with friends and relatives, might produce continued mental stimulation and better cognitive strategies or increase neural growth and synaptic density, thus delaying cognitive impairment (Zunzunegui et al., 2003). Furthermore, social networks may facilitate access to health care and healthy 
behaviors, thereby indirectly reducing or forestalling brain pathology and other conditions that affect cognition (Crooks et al., 2008).

Another hypothesis includes a contrary relationship between social networks and cognitive function. People with a better neural structure (i.e., more resistant to late damage and cognitive decline) may be better able to acquire and maintain social abilities and contacts (Zunzunegui et al., 2003). Furthermore, individuals with more frequent contacts with others have more opportunities for engagement with others, which may protect against cognitive decline through effects on positive emotional and cognitive states such as self-esteem, social competence, and adequate mood (Berger, Fratiglioni, Forsell, Winblad, \& Backman, 1999; Devanand, Sano, Tang, Taylor, Gurland, Wilder, et al., 1996).

With regard to the second dimension of social support, satisfaction with contacts, the data suggest a significant relationship between low or fair satisfaction with contacts and the risk for depressive symptoms alone and the co-occurrence of depressive symptoms and cognitive impairment. This relation is consistent with previous findings (Fuhrer et al., 1992) that indicate that lack of satisfaction with social support increased the risk of depressive symptoms alone and the co-occurrence of depressive symptoms and cognitive impairment. Other studies confirmed the influence of subjective measures of social support, including satisfaction with social support (Chi \& Chou, 2001; Cornman et al., 2003) and feelings of loneliness (Bisschop et al., 2004), on depressive symptoms in elderly individuals. Support of the elderly in Spain increases physical and mental health practices, reduces stress through emotional support, and facilitates more efficient caregiving (Zunzunegui et al., 2001).

The results of the current study suggest that the qualitative aspects of social support are more related to depressive symptoms than are the quantitative aspects such as social network size. However, these findings should be cautiously considered due to wide confidence intervals in some data, which may be due to the diversity of individual needs in terms of social contact. Extent of contact with others may not be an adequate predictor of emotional status because the number or frequency of social relationships required by each person may be influenced by personality and/or contextual variables. These data were obtained using the original 15-item Geriatric Depression Scale, and a cut-off point of 6 or higher was considered. Following the collection of the current data, in 2002, Martínez, Onís, Dueñas, Aguado, Albert, and Luque (2002) adapted and validated the abbreviated version of the Geriatric Depression Scale to the Spanish language and found a higher sensibility $(81.1 \%)$ and specificity $(76.7 \%)$ for a cut-off point of 5 or more. Thus, the present data may underestimate the number of people with depressive symptomatology, suggesting that social support may have a stronger effect on depressive symptomatology than indicated in the current study.

Recent studies found that quantitative aspects also significantly affected depressive symptomatology among older adults (Chan et al., 2011; Chiao et al., 2011). Moreover, Litwin (2011) reported that the structure of the network seems to matter more than the perceived quality of the ties as an indicator of depressive symptoms.

The last dimension of the assessed social support, the availability of someone who could provide help if the elderly individual was sick or disabled, was unrelated to the three study groups (i.e., not linked to either cognitive impairment or depressive symptoms). In contrast, previous research (Koizumi, Awata, Kuriyama, Ohmori, Hozawa, Seki, et al., 2005) showed a higher risk of depression with the lack of social support (having someone who can take care of you when you are ill in bed). The lack of significant results in the present study may be due to the high percentage of participants reporting the long-term availability of someone to provide help if sick or disabled and the low percentage of subjects reporting the unavailability of help.

This investigation provides interesting and practical approaches. First, mental health assessment should include both quantitative and qualitative aspects of social support. Moreover, both aspects should be considered in all socio-sanitary policies that promote social support in the elderly population with the aim of health promotion. This social support should consider the importance of the extent and frequency of social networks and the subjective satisfaction with such support.

Although the results of the study are interesting, this research is based on cross-sectional data, and longitudinal data are needed to further understand the causal and temporal relations between the studied variables. Therefore, future longitudinal research is required to make causal inferences between the various components of social support and mental health in older adults. In conclusion, the results demonstrate how various dimensions of social support affect the mental health of elderly adults.

These findings demonstrate that a limited amount of contact with others is related to the development of cognitive impairment, whereas the lack of satisfaction with social support is linked to changes in depressive symptoms and the co-occurrence of cognitive impairment and depressive symptoms. Therefore, an extensive social network and a feeling of satisfaction with the received social support received appear to be critical aspects for ensuring adequate mental health in older adults. 


\section{Acknowledgment}

We sincerely thank the Narón Council for providing access to their elderly population.

\section{References}

Barnes, L. L., Mendes de Leon, C. F., Wilson, R. S., Bienias, J. L., \& Evans, D. A. (2004). Social resources and cognitive decline in a population of older African Americans and whites. Neurology, 63, 2322-2326.

Bassuk, S. S., Glass, T. A., \& Berkman, L. F. (1999). Social disengagement and incident cognitive decline in community-dwelling elderly persons. Annals of Internal Medicine, 131, 165-173.

Berger, A. K., Fratiglioni, L., Forsell, Y., Winblad, B., \& Backman, L. (1999). The occurrence of depressive symptoms in the preclinical phase of AD. Neurology, 53, 1998-2002.

Bisschop, M. I., Kriegsman, D. M., Beekman, A. T., \& Deeg, D. J. H. (2004). Chronic diseases and depression: The modifying role of psychosocial resources. Social Science \& Medicine, 59, 721-733.

Brummett, B. H., Barefoot, J. C., Siegler, I. C., \& Steffens, D. C. (2000). Relation of subjective and received social support to clinical and self-report assessments of depressive symptoms in an elderly population. Journal of Affective Disorders, 61, 41-50.

Chan, A., Malhotra, C., Malhotra, R., \& Østbye, T. (2011). Living arrangements, social networks and depressive symptoms among older men and women in Singapore. International Journal of Geriatric Psychiatry, 26, 630-639. Chao, S. F. (2011). Assessing social support and depressive symptoms in older Chinese adults: A longitudinal perspective. Aging \& Mental Health, 15, 765-774.

Charlson, M. E., Pompei, P., Ales, K. L., \& MacKenzie, C. R. (1987). A new method of classifying prognostic comorbidity in longitudinal studies: Development and validation. Journal of Chronic Diseases, 40, 373-383.

Chi, I., \& Chou, K- L. (2001). Social support and depression among elderly Chinese people in Hong Kong. The International Journal of Aging and Human Development, 52, 231-252.

Chiao, C., Weng, L. J., \& Botticello, A. L. (2011). Social participation reduces depressive symptoms among older adults: An 18-year longitudinal analysis in Taiwan. BMC Public Health, 11, 292.

Cornman, J. C., Goldman, N., Glei, D. A., Weinstein, M., \& Chang, M. C. (2003). Social ties and perceived support: Two dimensions of social relationships and health among the elderly in Taiwan. Journal of Aging and Health, 15, 616-644.

Crooks, V. C., Lubben, J., Petitti, D. B., Little, D., \& Chiu, V. (2008). Social network, cognitive function, and dementia incidence among elderly women. The American Journal of Public Health, 98, 1221-1227.

Crum, R. M., Anthony, J. C., Bassett, S. S., \& Folstein, M. F. (1993). Population-based norms for the Mini-Mental State Examination by age and educational level. The Journal of the American Medical Association, 269, 23862391.

Devanand, D. P., Sano, M., Tang, M., Taylor, S., Gurland, B. J., Wilder, D., et al. (1996). Depressed mood and the incidence of Alzheimer's disease in the elderly living in the community. Archives of General Psychiatry, 53, 175182

Duke University. (1978). Multidimensional functional assessment: The OARS method - ology (2nd ed.). Durham, NC: Center for the Study of Aging and Human Development, Duke University.

Fillenbaum, G. G. (1988). Multidimensional functional assessment of older adults: The Duke Older Americans Resources and Services procedures . Hillsdale, NJ: Lawrence Erlbaum Associates.

Folstein, M. F., Folstein, S. E., \& McHugh, P. R. (1975). "Mini-Mental State." A practical method for grading the cognitive state of patients for the clinician. Journal of Psychiatric Research, 12, 189-198.

Fratiglioni, L., Wang, H. X., Ericsson, K., Maytan, M., \& Winblad, B. (2000). Influence of social network on occurrence of dementia: A community-based longitudinal study. The Lancet, 355, 1315-1319.

Fuhrer, R., Antonucci, T. C., \& Dartigues, J. F. (1992). The co-occurrence of depressive symptoms and cognitive impairment in a French community: Are there gender differences. European Archives of Psychiatry and Clinical Neuroscience, 242, 161-171.

Gabryelewicz, T., Styczynska, M., Pfeffer, A., Wasiak, B., Barczak, A., Luczywek, E., et al. (2004). Prevalence of major and minor depression in elderly persons with mild cognitive impairment-MADRS factor analysis. International Journal of Geriatric Psychiatry, 19, 1168-1172.

Glei, D. A., Landau, D. A., Goldman, N., Chuang, Y. L., Rodríguez, G., \& Weinstein, M. (2005). Participating in social activities helps preserve cognitive function: An analysis of a longitudinal, population-based study of the elderly. International Journal of Epidemiology, 34, 864-871.

Grau, G., Eiroa, P., \& Cayuela, A. (1996). Versión española del OARS multidimensional Functional Assessment Questionnaire: Adaptación transcultural y medida de la validez [Spanish version of the OARS Multidimensional Functional Assessment Questionnaire: cross-cultural adaptation and validity measurement]. Atención Primaria, 17 (8), 486-495

Green, A. F., Rebok, G., \& Lyketsos, C. G. (2008). Influence of social network characteristics on cognition and functional status with aging. International Journal of Geriatric Psychiatry, 23, 972-978.

Herrmann, N., Mittmann, N., Silver, I. L., Shulman, K. I., Busto, U. A., Shear, N. H., et al. (1996). A validation study of the geriatric depression scale short form. International Journal of Geriatric Psychiatry, 11, 457-460.

Holtzman, R. E., Rebok, G. W., Saczynski, J. S., Kouzis, A. C., Wilcox Doyle, K., \& Eaton, W. W. (2004). Social network characteristics and cognition in middle-aged and older adults. The Journals of Gerontology Series B: Psychological Sciences and Social Sciences, 9, P278-P284. 
Hughes, T. F., Andel, R., Small, B. J., Borenstein, A. R., \& Mortimer, J. A. (2008). The association between social resources and cognitive change in older adults: Evidence from the Charlotte County Healthy Aging Study. The Journals of Gerontology Series B: Psychological Sciences and Social Sciences, 63, P241-P244.

INE (Instituto Nacional de Estadística). (2000). Population Demographic Censuses. Municipal Register 2000 .

Katz, S., Ford, A. B., Moskowitz, R. W., Jackson, B. A., \& Jaffe, M. W. (1963). Studies of illness in the aged. The index of ADL: A standardized measure of biological and psychological function. The Journal of the American Medical Association, 185, 914-919.

Koizumi, Y., Awata, S., Kuriyama, S., Ohmori, K., Hozawa, A., Seki, T., et al. (2005). Association between social support and depression status in the elderly: Results of a 1-year community-based prospective cohort study in Japan. Psychiatry and Clinical Neurosciences, 59, 563-569.

Krueger, K. R., Wilson, R. S., Kamenetsky, J. M., Barnes, L. L., Bienias, J. L., \& Bennett, D. A. (2009). Social engagement and cognitive function in old age. Experimental Aging Research, 35, 45-60.

Lawton, M. P., \& Brody, E. M. (1969). Assessment of older people: Self-maintaining and instrumental activities of daily living. The Gerontologist, 9, 179-186.

Lee, Y., \& Shinkai, S. (2005). Correlates of cognitive impairment and depressive symptoms among older adults in Korea and Japan. International Journal of Geriatric Psychiatry, 20, 576-586.

Leung, K. K., Chen, C. Y., Lue, B. H., \& Hsu, S. T. (2007). Social support and family functioning on psychological symptoms in elderly Chinese. Archives of Gerontology and Geriatrics, 44, 203-213.

Litwin, H. (2011). The association between social network relationships and depressive symptoms among older Americans: What matters most? International Psycho-geriatrics, 23, 930-940.

Lobo, A., Ezquerra, J., Gómez Burgada, F., Sala, J. M., \& Seva Diaz, A. (1979). El mini-examen cognoscitivo: Un test sencillo, práctico, para detectar alteraciones intelectuales en pacientes médicos [Cognoctive mini-test: A simple practical test to detect intellectual changes in medical patients]. Actas Luso-Españolas de Neurología y Psiquiatria, 3, 189-202.

Martínez, J., Onís, M. C., Dueñas, R., Aguado, C., Albert, C., \& Luque, R. (2002). Versión española del cuestionario de Yesavage abreviado (GDS) para el cribado de depresión en mayores de 65 años. Adaptación y validación [The Spanish version of the Yesavage abbreviated questionnaire (GDS) to screen depressive dysfunctions in patients older than 65 years]. Medifam, 12, 620-630.

Mechakra-Tahiri, S., Zunzunegui, M. V., Préville, M., \& Dubé, M. (2009). Social relationships and depression among people 65 years and over living in rural and urban areas of Quebec. International Journal of Geriatric Psychiatry, 24, 1226-1236.

Millán-Calenti, J. C., Maseda, A., Rochette, S., Vázquez, G. A., Sánchez, A., \& Lorenzo, T. (2011). Mental and psychological conditions, medical comorbidity and functional limitation: Differential associations in older adults with cognitive impairment, depressive symptoms and co-existence of both. International Journal of Geriatric Psychiatry, 26, 1071-1079.

Prince, M. J., Harwood, R. H., Blizard, R. A., Thomas, A., \& Mann, A. H. (1997). Social support deficits, loneliness and life events as risk factors for depression in old age. The Gospel Oak Project VI. Psychological Medicine, 27, 323-332.

Scarmeas, N., \& Stern, Y. (2003). Cognitive reserve and lifestyle. Journal of Clinical and Experimental Neuropsychology, 25, 625-633.

Seeman, T. E., Albert, M., Lusignolo, T. N., \& Berkman, L. (2001). Social relationships, social support, and patterns of cognitive aging in healthy, high-functioning older adults: MacArthur studies of successful aging. Health Psychology, 20, 243-255.

Sheikh, J. I., \& Yesavage, J. A. (1986). Geriatric Depression Scale (GDS). Recent evidence and development of a shorter version. Clinical Gerontologist, 5, 165-172. SPSS Inc. (2007).

SPSS Base 16.0 for Windows User's Guide . Chicago, IL: Prentice Hall Press.

Steffens, D. C., \& Potter, G. G. (2008). Geriatric depression and cognitive impairment. Psychological Medicine, 38, $163-175$

Vinyoles Bargalló, E., Vila Domènech, J., Argimon Pallàs, J. M., Espinàs Boquet, J., Abos Pueyo, T., Limón Ramírez, E., \& Los investigadores del proyecto Cuida'l. (2002). Concordancia entre el Mini-Examen Cognoscitivo y el Mini-Mental State Examination en el cribado del déficit cognitivo [Concordance among MiniExamen Cognoscitivo and Mini-Mental State Examination in cognitive impairment screening]. Atención Primaria, 30, 5-13.

Yeh, S. C., \& Liu, Y. Y. (2003). Influence of social support on cognitive function in the elderly. BMC Health Services Research, 3,9.

Zunzunegui, M. V., Alvarado, B. E., Del Ser, T., \& Otero, A. (2003). Social networks, social integration, and social engagement determine cognitive decline in community- dwelling Spanish older adults. The Journals of Gerontology Series B: Psychological Sciences and Social Sciences, 58, S93-S100.

Zunzunegui, M-V., Béland, F., \& Otero, A. (2001). Support from children, living arrangements, self-rated health and depressive symptoms of older people in Spain. Inter- national Journal of Epidemiology, 30, 1090-1099. 